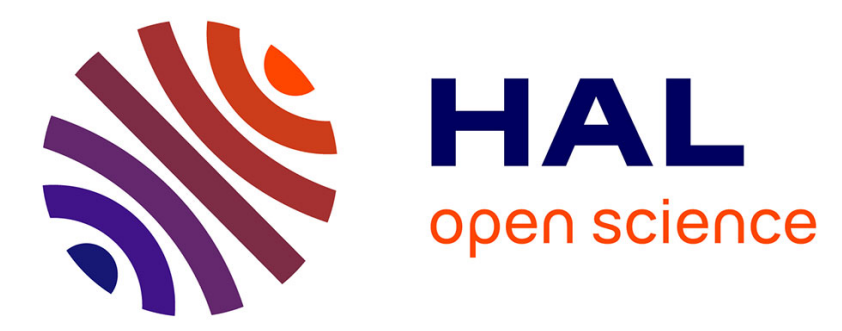

\title{
Micro-Nanostructured TiN Thin Film: Synthesis from a Photo-Patternable TiO2 Sol-Gel Coating and Rapid Thermal Nitridation
}

\author{
Arnaud Valour, Maria A Usuga Higuita, Nicolas Crespo-Monteiro, Stéphanie \\ Reynaud, Marion Hochedel, Damien Jamon, Christophe Donnet, Yves Jourlin
}

\section{To cite this version:}

Arnaud Valour, Maria A Usuga Higuita, Nicolas Crespo-Monteiro, Stéphanie Reynaud, Marion Hochedel, et al.. Micro-Nanostructured TiN Thin Film: Synthesis from a Photo-Patternable TiO2 Sol-Gel Coating and Rapid Thermal Nitridation. Journal of Physical Chemistry C, 2020, 124 (46), pp.25480 - 25488. 10.1021/acs.jpcc.0c07157 . hal-03273370

\section{HAL Id: hal-03273370 \\ https://hal.science/hal-03273370}

Submitted on 29 Jun 2021

HAL is a multi-disciplinary open access archive for the deposit and dissemination of scientific research documents, whether they are published or not. The documents may come from teaching and research institutions in France or abroad, or from public or private research centers.
L'archive ouverte pluridisciplinaire HAL, est destinée au dépôt et à la diffusion de documents scientifiques de niveau recherche, publiés ou non, émanant des établissements d'enseignement et de recherche français ou étrangers, des laboratoires publics ou privés. 


\title{
Micro-Nanostructured TiN Thin Film: Synthesis from a Photo- Patternable $\mathrm{TiO}_{2}$ Sol-Gel Coating and Rapid Thermal Nitridation
}

\author{
Arnaud Valour, Maria A. Usuga Higuita, Nicolas Crespo-Monteiro,* Stéphanie Reynaud, \\ Marion Hochedel, Damien Jamon, Christophe Donnet, and Yves Jourlin*
}

Cite This: J. Phys. Chem. C 2020, 124, 25480-25488

Read Online

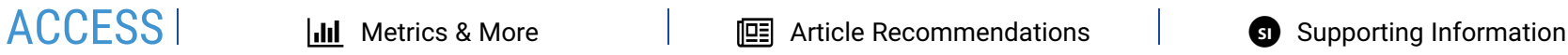

ABSTRACT: The miniaturization of optical components to control and manipulate light amplitude, phase, and polarization requires micro- to nanostructured metasurfaces that provide resonant light-matter interactions to exploit optical properties in the visible and near-infrared (NIR) range (plasmonic resonances, wavelength filtering, etc.). Such metasurfaces sometimes need to be implemented under hard-use conditions, including high temperatures and strong field confinement. Transition-metal nitrides, like titanium nitride (TiN), are ideal materials to achieve such properties, but TiN's hardness and chemical inertness make patterning difficult. Here, we present an innovative direct fabrication process to easily synthesize a micro-nanostructured $\mathrm{TiN}$ thin film. The technological process is based on a direct photo-patternable titanium oxide $\mathrm{TiO}_{2}$ sol-gel layer converted into $\mathrm{TiN}$ with a rapid thermal nitridation process. The nanoarchitecture and chemical composition of $\mathrm{TiO}_{2}$ and $\mathrm{TiN}$ films were investigated by ultraviolet (UV)visible-infrared (IR) spectroscopy and Raman spectroscopy, grazing incidence X-ray

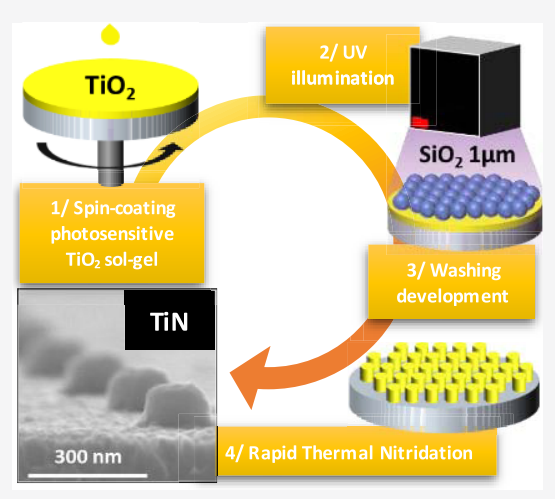
diffraction (GIXRD), and high-resolution transmission electron microscopy (HRTEM) coupled with electron energy loss spectroscopy (EELS). We obtained micro-nanotextured crystallized TiN surfaces in a significantly shorter time than with conventional nitridation processes. Due to the sol-gel approach, this work also significantly extends the chances of obtaining TiNbased metasurfaces on various substrates (glasses, plastics, etc.) in complex shapes (non-planar-based surfaces), for demanding photonic applications in the future.

\section{INTRODUCTION}

Optical metasurfaces are electromagnetic interfaces that can control and manipulate many properties of light, such as amplitude, phase, and polarization. ${ }^{1}$ These surfaces are composed of grating micro-nanostructures or antennas that undergo a resonant light-matter interaction with incoming electromagnetic radiation. ${ }^{2,3}$ Their ability to control light locally has aroused great interest in recent years, particularly for the miniaturization of optical components. ${ }^{1,4}$ The first metal-based optical metasurfaces were manufactured with conventional plasmonic materials such as gold and silver. However, these materials have many limitations for certain applications. Even though noble metals are good candidates for lossless plasmonic applications, silver has low chemical stability, gold is easily diffused into the substrate, and both metals have low melting temperatures. Consequently, noble metal nanostructures deform easily under high temperatures, thereby limiting their use in metasurface applications. New plasmonic materials are thus needed for stronger field confinement and high-temperature applications beyond the capabilities of noble metals. ${ }^{1}$ Among such materials, titanium nitride (TiN) is one of the most promising compounds investigated to date. ${ }^{5,6} \mathrm{TiN}$ can be obtained using a wide range of physical vapor deposition (PVD) and chemical vapor deposition (CVD) processes requiring vacuum technology, such as reactive magnetron sputtering, ${ }^{5,7-10}$ molecular-beam epitaxy, ${ }^{11,12}$ chemical vapor deposition (CVD), ${ }^{13-15}$ atomic layer deposition (ALD), ${ }^{16-19}$ or pulsed laser deposition (PLD) ${ }^{20-22}$ under a nitrogen or ammonia atmosphere. Unfortunately, due to its intrinsic properties, notably hardness and chemical resistance, TiN cannot easily form micro- and nanostructures. Structuring techniques using lithography and liftoff and/or physical or chemical etching processes do exist ${ }^{21}$ but are restrictive and time-consuming. The size and shape of the substrates are also limiting for these techniques since they are constrained to planar microelectronic technologies. Another recent method consists of performing micro-nanostructuring on $\mathrm{TiO}_{2}$ sol-gel photopatternable film that is then converted into TiN using a thermal nitridation process in an ammonia atmosphere. ${ }^{23}$ The main advantage of the sol-gel-based processes is that they make it possible to achieve submicronic structuration with various

Received: September 4, 2020

Revised: October 15, 2020

Published: November 5, 2020

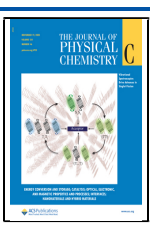


reproducible shapes (like grating, ${ }^{23}$ pillars, ${ }^{24}$ etc.) on large surface $\operatorname{areas}^{24}$ and without unconventional shape restrictions. ${ }^{25,26}$ Generally, nitridation processes of $\mathrm{TiO}_{2}$ films are achieved in traditional ovens with a long exposure time at high temperatures (more than $900-1000{ }^{\circ} \mathrm{C}$ for several hours), ${ }^{27-29}$ which limits their use for stable substrates at high temperatures and also limits their industrial deployment. Rapid thermal nitridation (RTN) appears to be a very promising alternative way to synthesize high-quality $\mathrm{TiN}$ sub-microstructured thin films with complex shapes on a wide range of substrates at significantly shorter heating times and under less stringent conditions. Here, we demonstrate how to obtain micronanostructured TiN films by combining a direct ultraviolet (UV)-photolithography process with rapid thermal nitridation from a photo-patternable $\mathrm{TiO}_{2}$ sol-gel coating using a low-cost, reproducible process that is compatible with large substrate areas and different shapes. For example, this technique could be potentially useful in the manufacturing of optical metasurface devices or new plasmonic materials.

\section{EXPERIMENTAL SECTION}

2.1. Elaboration of $\mathrm{TiO}_{2}$ Films. The films used in this study were elaborated following a previously published procedure. $^{23,24,30,31}$ To optimize photo-patternable films, two sols were mixed. The first sol (sol 1) was prepared by reacting tetraisopropylorthotitanate (TIPT from Fluka) with benzoylacetone (BzAc from Aldrich) in methyl alcohol ( $\mathrm{MeOH}$ from Prolabo). The TIPT/BzAc/MeOH molar composition was $1 /$ $0.91 / 20.4$. The second sol (sol 2) was prepared by mixing TIPT with deionized water, hydrochloric acid ( $\mathrm{HCl}$ from Roth), and butyl alcohol (BuOH from Alfa Aesar) as a solvent. The TIPT concentration in the solution was $0.4 \mathrm{M}$, and the TIPT $/ \mathrm{H}_{2} \mathrm{O}$ / $\mathrm{HCl} / \mathrm{BuOH}$ molar composition was $1 / 0.82 / 0.13 / 23.9$. The photo-patternable solution was prepared by mixing sols 1 and 2 to obtain a final sol with a TIPT concentration of $0.6 \mathrm{M}$ and a BzAc/TIPT molar ratio of 0.6. The sol was deposited on a silicate substrate by spin-coating at $3000 \mathrm{rpm}$ for $1 \mathrm{~min}$. The resulting sol-gel film was heated at $110^{\circ} \mathrm{C}$ for $90 \mathrm{~min}$, resulting in a so-called xerogel film, i.e., an inorganic polymer film made of $\mathrm{Ti}-\mathrm{O}-\mathrm{Ti}$ chains with organic chain-end groups arising from the sol formulation, mainly TIPT-BzAc complexed species. The thickness of the resulting thin-film layer was close to $300 \mathrm{~nm}$.

2.2. Film Photo-Structuring Process. The xerogel films are soluble in different solvents (alcohol, chloroform, acetone, etc.) as long as BzAc remains complexed with TIPT. The main strength of this protocol is the properties of BzAc, which make the film soluble in a solvent while remaining sensitive to UVA light. Indeed, under UVA illumination, the TIPT-BzAc complex is partially degraded into insoluble species such as carbonates and/or carboxylates. It therefore creates a contrast of solubility between illuminated and nonilluminated areas when it is spatially selectively exposed to UVA light, such as a negative photosensitive layer. In our first experimental demonstration, microstructuring films were obtained by illuminating xerogel films through a chromium photomask for 5 min under a $365 \mathrm{~nm}$ wavelength collimated light, from a UV photomask exposure machine (SET 700 photomask machine) with an irradiance of $26 \mathrm{~mW} \cdot \mathrm{cm}^{-2}$, which led to the production of linear gratings of 1 $\mu \mathrm{m}$ period. The photochemical or thermochemical effects of this step process are described in previous work. ${ }^{30}$ In the present study, the nanostructured $\mathrm{TiO}_{2}$ films were made using microsphere photolithography to obtain amorphous $\mathrm{TiO}_{2}$ nanopillars, according to the procedure published in ref $24 .^{24}$
The Langmuir-Blodgett (LB) technique was used to deposit a 1 $\mu \mathrm{m}$ silica microsphere monolayer with an acrylate surface (suspension in ethanol $(96 \% \mathrm{v} / \mathrm{v})$ Micromod) on an amorphous $\mathrm{TiO}_{2}$ xerogel film using an LB machine (KSV NIMA LB) from Biolin Scientific. The subphase was made using deionized water. The monolayer of silica microspheres was spread on the aqueous subphase at room temperature. The monolayer was left for 10 min for the solvent to evaporate. After compression of the silica microsphere monolayer at a barrier speed of $2 \mathrm{~mm} \mathrm{~min}^{-1}, \mathrm{LB}$ was deposited on the $\mathrm{TiO}_{2}$ thin film (deposited on a $\mathrm{SiO}_{2}$ substrate) at a surface pressure of $35 \mathrm{mN} \cdot \mathrm{m}^{-1}$ using the dipping method at a withdrawal speed of $1 \mathrm{~mm} \min ^{-1}$. After the homogeneous deposition of two-dimensional (2D) hexagonal microspheres, the films were first illuminated with homogeneous UV light to create the nanopillars according to a $2 \mathrm{D}$ hexagonal microsphere pattern. The exposure film was then developed by soaking it in ethanol for $30 \mathrm{~s}$ and finally rinsing it in deionized water for a further $30 \mathrm{~s}$. Ethanol dissolves the noninsolated xerogel layer and water stabilizes it, leading to a pattern that is the same as the one of the photomask, or in the case of the microsphere photolithography, leading to nanopillars. The amorphous-structured $\mathrm{TiO}_{2}$ thin film was then nitrided by rapid thermal annealing (RTA) under $\mathrm{NH}_{3}$ gas. According to Kamiya et al., ${ }^{27,32}$ the nitridation under heating is performed via the following reactions of $\mathrm{NH}_{3}$ with the reduced titanium dioxide

$$
\begin{aligned}
& 2 \mathrm{NH}_{3} \rightarrow \mathrm{N}_{2}+3 \mathrm{H}_{2} \\
& 2 \mathrm{TiO}_{2}+\mathrm{H}_{2} \rightarrow \mathrm{Ti}_{2} \mathrm{O}_{3}+\mathrm{H}_{2} \mathrm{O} \\
& \mathrm{Ti}_{2} \mathrm{O}_{3}+2 \mathrm{NH}_{3} \rightarrow 2 \mathrm{TiN}+3 \mathrm{H}_{2} \mathrm{O}
\end{aligned}
$$

Rapid thermal nitridation treatment of this film was done using an RTA As-One 100 furnace from Annealsys under pure $\mathrm{NH}_{3}$. Samples are treated in a reproducible and uniform way using a system of 12 high-intensity halogen near-infrared (NIR) light sources. Initially, the reactor was purged with a cycle of $\mathrm{N}_{2}(1000$ sccm) and vacuum. We use the RTA furnace with a configuration that unfortunately does not allow us to know precisely the temperature used during our process, which is why we only indicate a percentage of lamp power. The samples are irradiated for $30 \mathrm{~s}$ at $30 \%$ lamp power 10 times in a row (with a 1 $\mathrm{s}$ at $1 \%$ lamp power between each heat treatment to preserve the lamps and maximize their lifetime) for a total NIR exposure time of $10 \mathrm{~min}$. During the nitridation process, a $1000 \mathrm{sccm} \mathrm{NH} \mathrm{N}_{3}$ flow was introduced in the chamber at a pressure of $10 \mathrm{mbar}$.

2.3. Characterization. Several characterizations were performed to identify both the optical properties and structural/material properties of the resulting non-microstructured and microstructured thin films. The films were characterized before and after nitridation. UV-visible (vis)infrared (IR) spectrophotometric measurements (Cary 5000 UV-vis-NIR from Agilent Technologies) were performed in the infrared, visible, and near-UV spectral ranges. Reflection spectroscopy measurements were carried out in specular configuration with an incident angle of $10^{\circ}$. Raman microspectroscopy measurements (LabRam ARAMIS) were performed with excitation at $633 \mathrm{~nm}$. Grazing incidence X-ray diffraction (GIXRD) was carried out to obtain a surfacesensitive diffraction signal representative of the crystalline structures of the Ti-based thin films. Measurements were obtained using a PANalytical MPD diffractometer delivering an $\mathrm{X}$-ray beam produced by a copper anti-cathode with a 

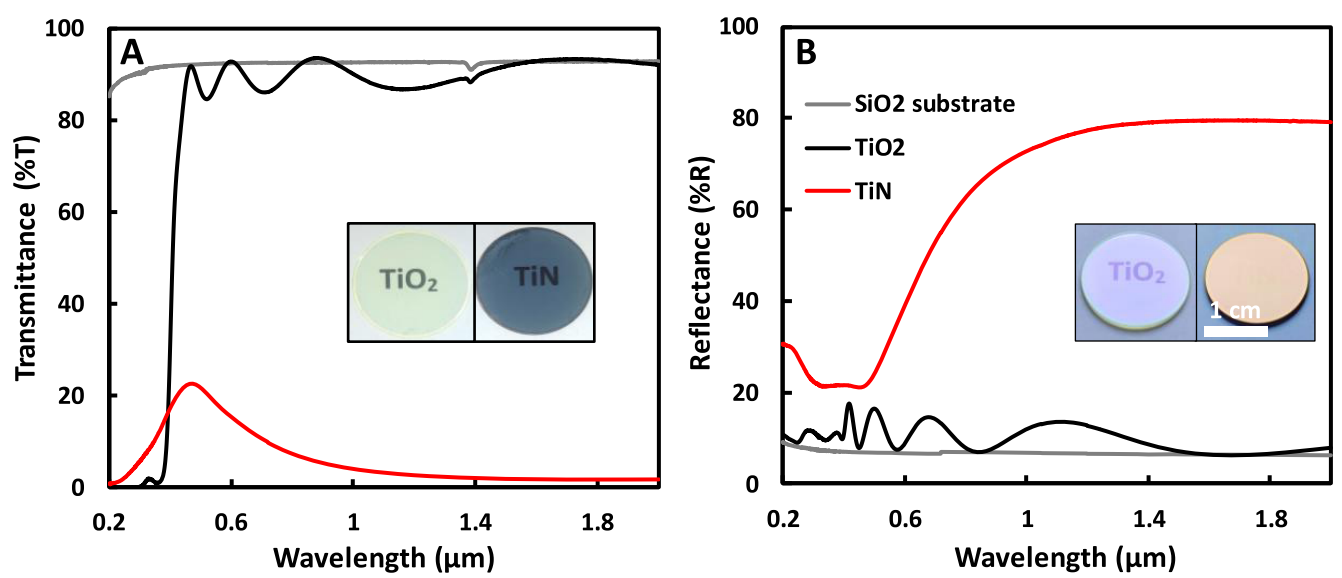

Figure 1. UV-visible-NIR reflectance (A) and transmittance (B) spectra of the glass substrate $\left(\mathrm{SiO}_{2}\right), \mathrm{TiO}_{2}$, and TiN thin films. Inset: A and B optical photographs of the same $\mathrm{TiO}_{2}$ and $\mathrm{TiN}$ thin films in transmission and specular reflections, respectively.

wavelength of $0.154 \mathrm{~nm}$. Acquisition was performed in the $2 \theta$ mode within 30 and $80^{\circ}$. Spectroscopic ellipsometry measurements (UVISEL from Horiba Jobin Yvon, associated with DeltaPsi2 software) were made to determine the refractive index $(n)$ and the extinction coefficient $(k)$ to deduce the corresponding $\varepsilon^{\prime}$ and $\varepsilon^{\prime \prime}$ values of permittivity of the $\mathrm{TiO}_{2}$ and TiN thin films. The surface roughness was determined using a Dimension Icon from Bruker AFM and the thickness of the film was measured with a profilometer Veeco Dektak 3 ST. Structural and chemical investigations were conducted with electron microscopy. First, focused ion beam (FIB) lamellas were extracted from the two samples using an FEI (Thermo Fisher) Helios 600i dual-beam FIB/scanning electron microscopy (SEM). The two lamellas were thinned at different $\mathrm{Ga}^{+}$ion voltages and currents, and were finally thoroughly cleaned down to $1 \mathrm{kV}$ to optimally remove ion beam artifacts, such as redeposition or amorphization. Then, bright-field transmission electron microscopy (BF-TEM), high-angle annular dark-field scanning TEM (HAADF STEM), and high-resolution TEM (HRTEM) pictures were produced on the lamellas using a JEOL Neo-ARM 200F transmission electron microscope. The NeoARM is a spherical aberration (Cs)-corrected TEM, equipped with a cold-field electron gun (cold-FEG). Electron-dispersive spectroscopy (EDS) was performed on both samples using a JEOL large-angle silicon drift detector (1sr SDD CENTURIO$\mathrm{XL}$ ). EDS mappings of nitrogen, oxygen, silicon and titanium were performed using the same ROI in the range of $0.36-0.45$, $0.49-0.56,1.64-1.84$, and $4.35-4.67 \mathrm{kV}$, respectively. Electron energy loss spectroscopy (EELS) and spectrum image (SI) data were collected in EELS mode together with HAADF STEM using a Gatan imaging filter (GIF Quantum ER) and a Gatan ADF STEM detector. Spectra and mapping were aligned and extracted from the dual-EELS SI raw data; the appropriate background was selected using DM software.

\section{RESULTS AND DISCUSSION}

3.1. Characterization of Titania Films. After deposition, the $\mathrm{TiO}_{2}$ films were transparent and slightly yellowish (Figure 1A). UV-vis-NIR transmittance analyses (black curve in Figure 1A) revealed a typical strong absorption band for the $\mathrm{TiO}_{2}$ thin film under $400 \mathrm{~nm}$, indicating its opacity in the UV region and hence its absorption in the $U V$ wavelength range. The curve of the film presents no other absorption band in the visible and near-infrared range, with a maximum transmittance higher than $80 \%$, indicating its transparency in this region. The oscillations present on the curve are due to the interference of the reflection of the light on the transparent substrate and film interfaces. This phenomenon depends on the refractive indexes and the thickness of the film. ${ }^{33}$ The reflectance curve agrees with the results in the transmission as shown in Figure 1A, with a reflectance lower than $20 \%$ and a slight purple color in reflection.

The thickness of the titania $\left(\mathrm{TiO}_{2}\right)$ film is estimated to be 300 $\mathrm{nm}$ from profilometry measurements and TEM pictures in cross section (Figure 4). Their Raman spectrum (Figure 2) shows

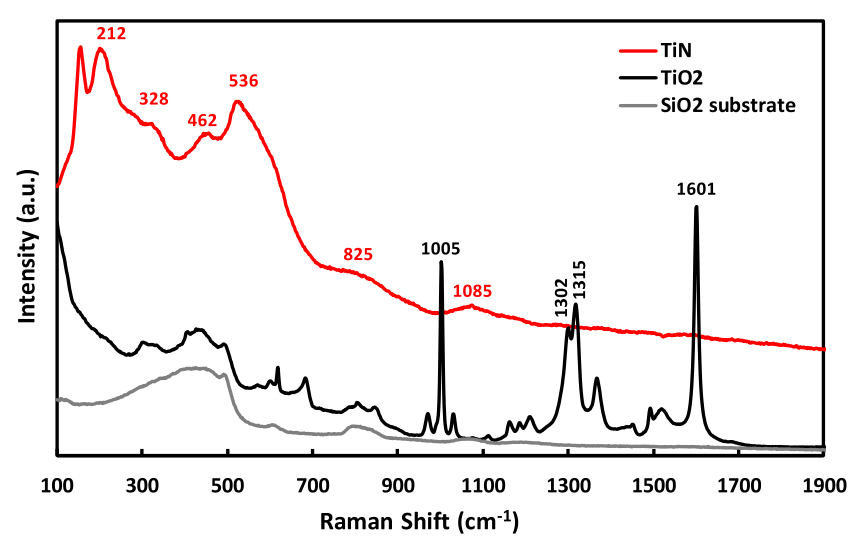

Figure 2. Raman spectra of a bare glass substrate $\left(\mathrm{SiO}_{2}\right), \mathrm{TiO}_{2}$, and $\mathrm{TiN}$ thin films.

multiple peaks but no features of crystallized $\mathrm{TiO}_{2}$. According to Oda et al., the strong peaks at 1601 and $1005 \mathrm{~cm}^{-1}$ are assigned to $8 \mathrm{~b}$ and 12 vibration modes of the phenyl group of $\mathrm{BzAc}$, and the peaks at 1302 and $1315 \mathrm{~cm}^{-1}$ can be attributed to $\mathrm{C}=\mathrm{C}=\mathrm{C}$ symmetric vibrations in chelating rings. ${ }^{34}$ The other weak Raman peaks are hypothesized to be related to the BzAc or $\mathrm{TiO}_{2} / \mathrm{BzAc}$ complex. It is clear from these results that the $\mathrm{TiO}_{2}$ layer is not pure and still contains organic functions, but to simplify the reading, we will retain the name $\mathrm{TiO}_{2}$ in the rest of the paper for xerogel comprising organic functions.

Grazing incidence X-ray diffraction (GIXRD) measurements (Figure 3) confirmed the absence of diffraction peaks related to crystallized phases of titania, indicating the amorphous character of the titania film (diffractogram in black). The diffractogram related to the amorphous silica substrate is also shown in Figure 3 (diffractogram in gray). 


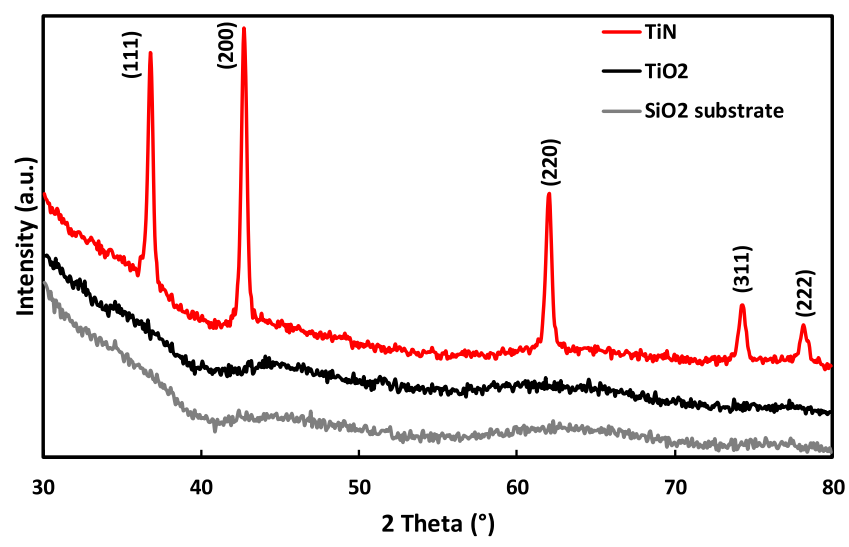

Figure 3. GIXRD patterns for a bare glass substrate $\left(\mathrm{SiO}_{2}\right)$, amorphous $\mathrm{TiO}_{2}$, and $\mathrm{TiN}$ thin films.

The amorphous nature of the $\mathrm{TiO}_{2}$ film can be inferred from EELS SI data (Figure 4). Indeed, the $\mathrm{Ti}_{2,3}$ edges at 456 and 462 $\mathrm{eV}$ are characteristic of the amorphous phase of $\mathrm{TiO}_{2}$. Furthermore, the spectrum shows slightly shouldered $\mathrm{Ti} \mathrm{L}_{2,3}$ edges that nevertheless indicate the presence of some nanocrystals in the film. ${ }^{35}$ Consequently, before irradiation, the films are considered to be homogeneous and mainly amorphous.

Spectroscopic ellipsometry measurements were performed to determine the optical constants of the films for wavelengths between 280 and $2000 \mathrm{~nm}$. The refractive index of the $\mathrm{TiO}_{2}$ amorphous thin films (Figure 5A) is estimated at around $n=2$ and 1.7 , respectively, in the visible region (for $\lambda=400 \mathrm{~nm}$ ) and the near-infrared region (for $\lambda$ from 1100 to $2000 \mathrm{~nm}$ ). Atomic force microscopy (AFM) measurement showed that the film has a relatively homogeneous morphology with a smooth surface. The calculated roughness is approximately $\mathrm{Ra} \approx 22 \mathrm{pm}$.

3.2. Conversion of a Titania Film into a Titanium Nitride Film. The xerogel films are subjected to a cycle of ten 30 $\mathrm{s}$ infrared flashes under a flow of ammonia at a flow rate of 1000 sccm and a pressure of 10 mbar. After treatment, the films are slightly transparent. They are grayish in color in transmission (Figure 1A) and have a burnished color in reflection (Figure 1B). The thickness of the TiN films is around $60 \mathrm{~nm}$, which is thinner than that of the amorphous $\mathrm{TiO}_{2}$ layers heated at $110^{\circ} \mathrm{C}$ $(250 \mathrm{~nm})$. The increase in the annealing temperature during the RTN causes densification of the film and thus reduces the thickness of the film. This densification causes a global shrinkage of around $75 \%$ of the original volume. The reflectance spectra indicate a minimum reflectance of $21 \%$ at wavelengths between
300 and $500 \mathrm{~nm}$ and a high reflection around $80 \%$ in nearinfrared wavelengths, revealing a change in the optical properties of the original film. This high reflectance in near IR highlights the metallic character of $\mathrm{TiN}^{37}$ compared to the pure dielectric behavior of the $\mathrm{TiO}_{2}$ layer. The transmittance spectrum of the TiN thin film confirmed these results with a broad absorption peak at wavelengths around $480 \mathrm{~nm}$ with a maximum transmittance of $22 \%$ and then decreased to $1-2 \%$ in the near-infrared region. The broad absorption signal in the visible region due to the incorporation of nitrogen into the film agrees with the gray coloring of the TiN sample. The spectroscopic ellipsometry measurements confirmed this statement; the refractive index changed at $n=5$ for $\lambda=2000 \mathrm{~nm}$ (Figure 5B). These results resemble those reported by Pflüger et al. ${ }^{36}$ for stoichiometric TiN. The real part of the refractive index $(n)$ differs slightly from the bulk value of the TiN, which can be explained by the porosity in the layer that reduces the real part of the refractive index. The $k$ value of the refractive index demonstrates absorption of the TiN thin layer, while it is equal to zero for the $\mathrm{TiO}_{2}$ thin layer in the visible wavelength range. From ellipsometry measurements, we can also deduce the corresponding values of the real $\left(\varepsilon^{\prime}\right)$ and the imaginary $\left(\varepsilon^{\prime \prime}\right)$ parts of permittivity with eq 4 as follows

$$
\varepsilon^{\prime}=n^{2}-k^{2} \quad \varepsilon^{\prime \prime}=2 n^{2} k^{2}
$$

The latter parameters are very important to confirm that the layer is a good material for the propagation of plasmonic waves since they determine the metallic properties of the layer. The $\varepsilon^{\prime}$ and $\varepsilon^{\prime \prime}$ values measured on the TiN layer as a function of the wavelength are illustrated, respectively, in Figure 6A,B. Our TiN film presents the lowest real permittivity $\varepsilon^{\prime} \approx-14$ for $\lambda=1600$ $\mathrm{nm}$. The metallic property was estimated with the absolute value of the real part of the permittivity $\left(\varepsilon^{\prime}\right)$ to be as large as possible. Concerning the imaginary part of the permittivity, $\varepsilon^{\prime \prime}$ evolves almost linearly as a function of the wavelength up to $\varepsilon^{\prime \prime}=60$ for $\lambda$ $=2000 \mathrm{~nm}$. We observe a lower metallic character in our TiN film compared to recent reports of plasmonic TiN obtained by the physical deposition method that may negatively affect the performance of the plasmonic metasurface that is fabricated out of them. ${ }^{21,38}$ This could be explained by the fact that our films present higher residual porosity due to the preparation method; the films prepared by the sol-gel route are generally less dense than those obtained by physical route deposition. As shown in the cross-sectional HAADF STEM images in Figure 7A, one can see a few pores that could explain the lower values of optical properties. This difference in density in our films could explain the lower metallic character in our TiN layer. The metallic
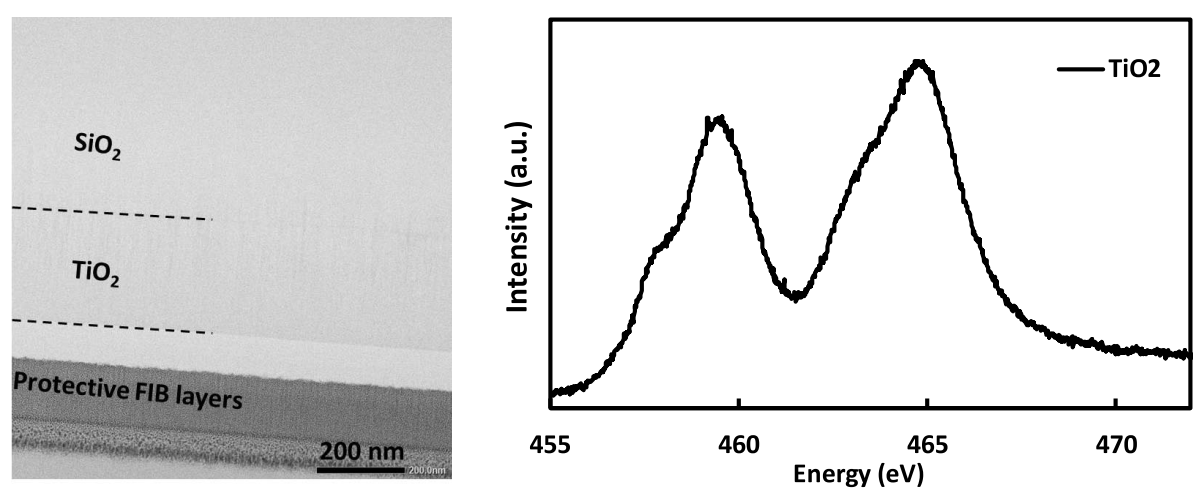

Figure 4. Cross-sectional high-resolution transmission electron microscopy image (left) and EELS spectrum (right) of the amorphous $\mathrm{TiO}_{2}$ thin film. 

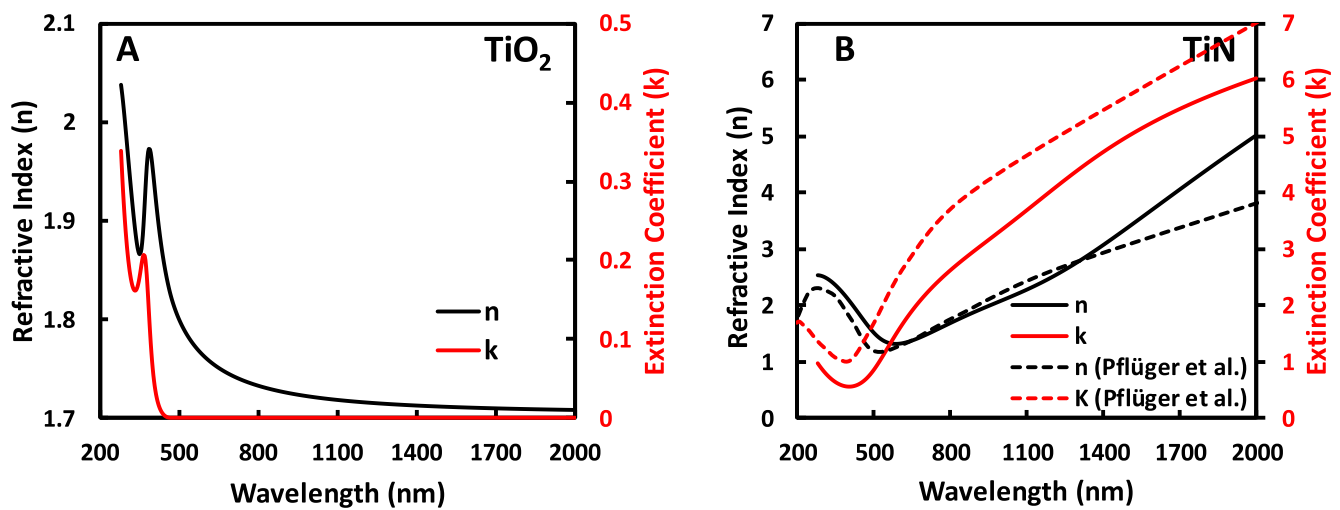

Figure 5. Refractive index $(n)$, extinction coefficient $(k)$ spectra of amorphous $\mathrm{TiO}_{2}(\mathrm{~A})$, and $\mathrm{TiN}(\mathrm{B})$ thin films compared with the values reported by Pflüger et al. ${ }^{36}$
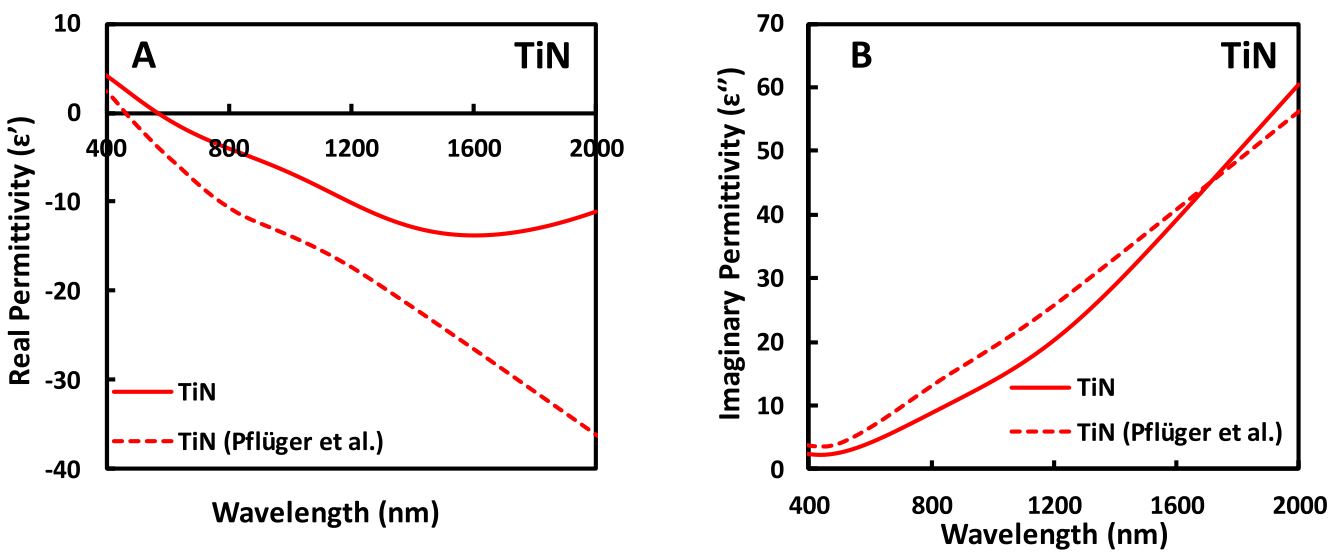

Figure 6. Permittivity according to the wavelength for a TiN film: (A) real part $\left(\varepsilon^{\prime}\right)$ and (B) imaginary part $\left(\varepsilon^{\prime \prime}\right)$ compared with the values reported by Pflüger et al. ${ }^{36}$

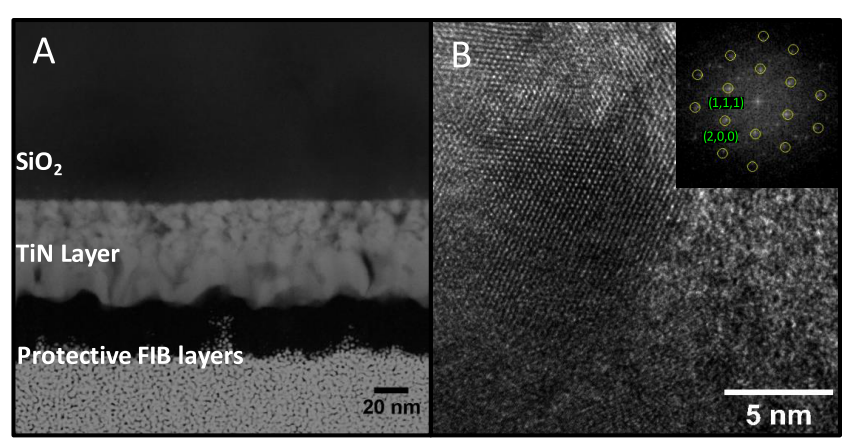

Figure 7. (A) Cross-sectional high-magnification HAADF STEM image of the TiN thin film and (B) HRTEM image of the same TiN layer. Inset: corresponding fast Fourier transform (FFT) showing the (111) and (200) directions of the TiN FCC structure. properties could be improved by reducing the porosity in our TiN layer, for example, by optimizing the preparation of the $\mathrm{TiO}_{2}$ solution or/and the nitriding conditions. In spite of this, these results enable us to conclude that the TiN layer could be used as a plasmonic layer in the NIR range, with reasonable losses, caused by the propagation length of the surface plasmon propagating along the metallic layer.

However, the roughness increases very slightly at $\mathrm{Ra} \approx 181$ $\mathrm{pm}$; the films therefore remain relatively flat and homogeneous. The Raman spectra carried out after RTA treatment revealed the presence of six dominant peaks at 212, 328, 462, 536, 825, and 1 $085 \mathrm{~cm}^{-1}$ (Figure 2). These values agree with the Raman-active modes of titanium nitride $(\mathrm{TiN})$ reported in the literature. ${ }^{39-41}$ The bands at 212 and $328 \mathrm{~cm}^{-1}$ are attributed to transverse acoustic (TA) and longitudinal acoustic (LA) modes, the band at $462 \mathrm{~cm}^{-1}$ to the second-order acoustic $(2 \mathrm{~A})$ mode, and the band at $536 \mathrm{~cm}^{-1}$ to the transverse optical (TO) mode of the

Table 1. Experimental $d_{(h k l)}$ and Relative Intensity $I(\%)$ Values of the Investigated Titanium Nitride Film, Compared to the $d_{(h k l)}$ and $I$ (\%) Values Related to the Osbornite TiN Reference ${ }^{42} a$

\begin{tabular}{|c|c|c|c|c|c|}
\hline & (111) & (200) & $(220)$ & (311) & $(222)$ \\
\hline $\mathrm{d}_{(h k l)}$ experimental $(\mathrm{nm})$ & 0.243963 & 0.211357 & 0.149461 & 0.127542 & 0.122137 \\
\hline $\mathrm{d}_{(h k l)}$ osbornite $\operatorname{TiN}(\mathrm{nm})$ & 0.243988 & 0.211300 & 0.149412 & 0.127419 & 0.121994 \\
\hline (d experimental- $\mathrm{d}$ osbornite) $/ \mathrm{d}$ osbornite $(\%)$ & $-0.01 \%$ & $+0.03 \%$ & $+0.03 \%$ & $+0.10 \%$ & $+0.12 \%$ \\
\hline$I(\%)$ experimental & 77.7 & 100.0 & 53.7 & 18.9 & 12.4 \\
\hline I (\%) osbornite TiN & 71.2 & 100.0 & 45.6 & 17.6 & 11.6 \\
\hline
\end{tabular}

${ }^{a}$ Relative shift between experimental $\mathrm{d}_{(h k l)}$ and osbornite $\mathrm{d}_{(h k l)}$ is also depicted for the five diffraction peaks. 

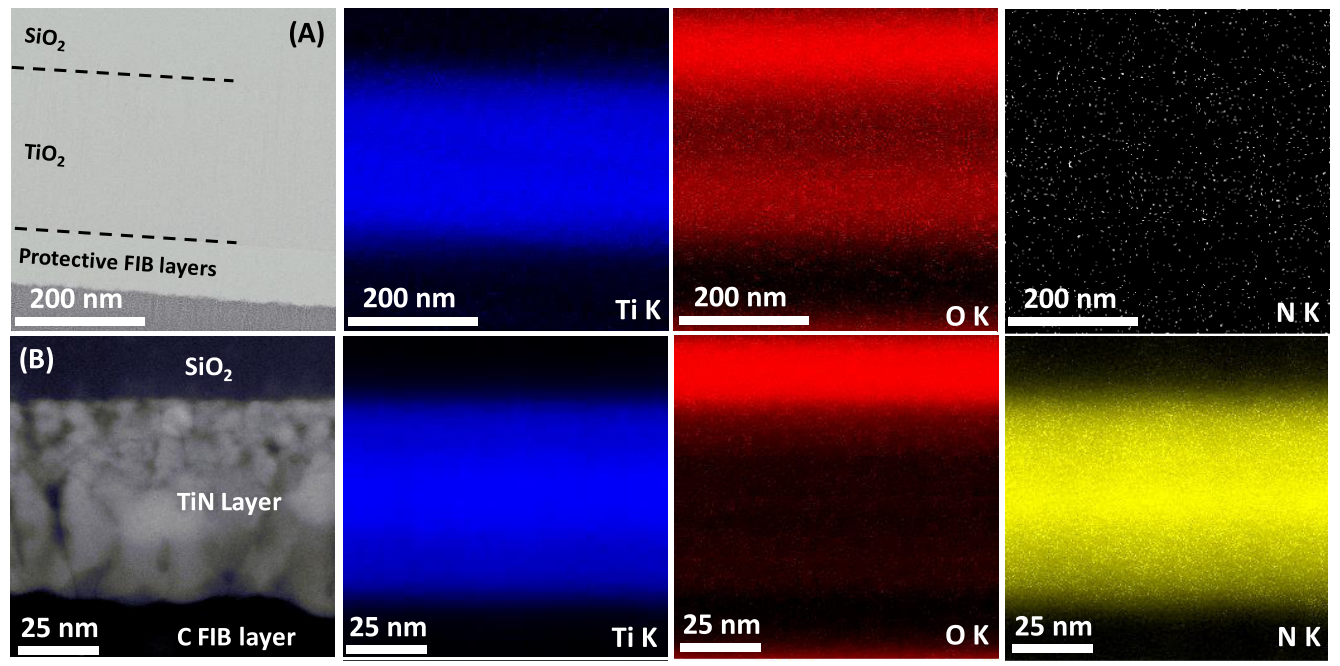

Figure 8. Cross-sectional high-resolution transmission electron microscopy image and EDS mapping images of the thin films related to (A) Ti, $\mathrm{O}$, and $\mathrm{N}$ elements in the $\mathrm{TiO}_{2}$ film and (B) $\mathrm{Ti}, \mathrm{O}$, and $\mathrm{N}$ elements in the TiN film.

TiN film. The two broad peaks at around 825 and $1085 \mathrm{~cm}^{-1}$ could be assigned to $\mathrm{LA}+\mathrm{TO}$ and $2 \mathrm{TO}$ modes of $\mathrm{TiN}$, respectively. The RTN process causes shrinkage, resulting in a film that is about $50 \mathrm{~nm}$ thick. The significant reduction in the thickness of the film results from the switch of the film from amorphous $\mathrm{TiO}_{2}$ to TiN. This structural transformation is also observed by GIXRD measurements, as shown in Figure 3. The GIXRD diffractogram related to the coating after irradiation by the infrared flashes under the ammoniac flow exhibits five diffraction peaks centered at $2 \theta=36.8115,42.7480,62.0465$, 74.3080 , and $78.2016^{\circ}$. After background subtraction, their relative intensities normalized to the most intense peak $\left(42.7480^{\circ}\right)$ are $77.7,100.0,53.7,18.9$, and $12.4 \%$, respectively. The Bragg indexation of those five peaks corresponds to a cubic phase with a space group $F m \overline{3} m$ (225), with a cell parameter of $0.4235 \mathrm{~nm}$. The most probable phase in agreement with this space group and cell parameter value is titanium nitride (TiN), whose diffraction peaks within the investigated diffraction range correspond to the crystalline planes (111), (200), (220), (311), and (222). Table 1 compares the experimental $\mathrm{d}_{(h k l)}$ and relative intensity $I(\%)$ values with those related to osbornite $\mathrm{TiN}$ as the reference crystalline phase. ${ }^{42}$ The relative shift between experimental and osbornite diffraction peaks (d experimental$\mathrm{d}$ osbornite)/d osbornite, depicted in Table 1 , ranges within $-0.01 \%$ and $+0.12 \%$, which demonstrates that the experimental TiN film is very similar to natural osbornite from a crystallographic point of view. The small shift may be attributed to some internal stress, whose quantification has not been investigated at the present stage of experimentation. The good agreement between the $\mathrm{d}_{(h k l)}$ and $I(\%)$ values of the investigated film and the reference TiN crystal indicates that the infrared flash irradiation of titania in the presence of ammonia unambiguously leads to the formation of a crystallized titanium nitride film.

The conversion of the titania film into the titanium nitride film is also confirmed by HRTEM diffractograms (Figure 7B) obtained on crystals inside the film, indicating the presence of a TiN crystalline phase (face-centered cubic (fcc) structure with a unit cell length of $0.4235 \mathrm{~nm}),{ }^{43}$ in agreement with the results of previous GIXRD investigations.

The cross-sectional HAADF STEM images in Figure 8A,B show well-defined $\mathrm{TiO}_{2}$ and $\mathrm{TiN}$ layers whose respective thicknesses are in agreement with profilometry measurements (around $250 \mathrm{~nm}$ for $\mathrm{TiO}_{2}$ and $60 \mathrm{~nm}$ for TiN). Figure 8A,B also shows the results of the STEM/EDS element mapping carried out on the $\mathrm{TiO}_{2}$ sample before and after RTN treatment. We can observe before nitridation a slight oxygen concentration gradient along the $z$-axis, which does not affect the quality of the layer after treatment under $\mathrm{NH}_{3}$. Currently, we do not know the causes of this gradient but studies are underway. EDS mapping of titanium, oxygen, and nitrogen on both samples (Figure 8) confirmed that the nitridation process was complete throughout the layer. These results are in full agreement with the EELS experiments carried out on the nitrided sample (Figure 9). Indeed, the energy loss spectrum corresponding to the nitrided sample shows, respectively, an $\mathrm{N} \mathrm{K}$ edge at $401 \mathrm{eV}$, a Ti $\mathrm{L}_{2,3}$ edge at 456 and $462 \mathrm{eV}$, and a reduced $\mathrm{O} \mathrm{K}$ edge at $532 \mathrm{eV}$. EELS
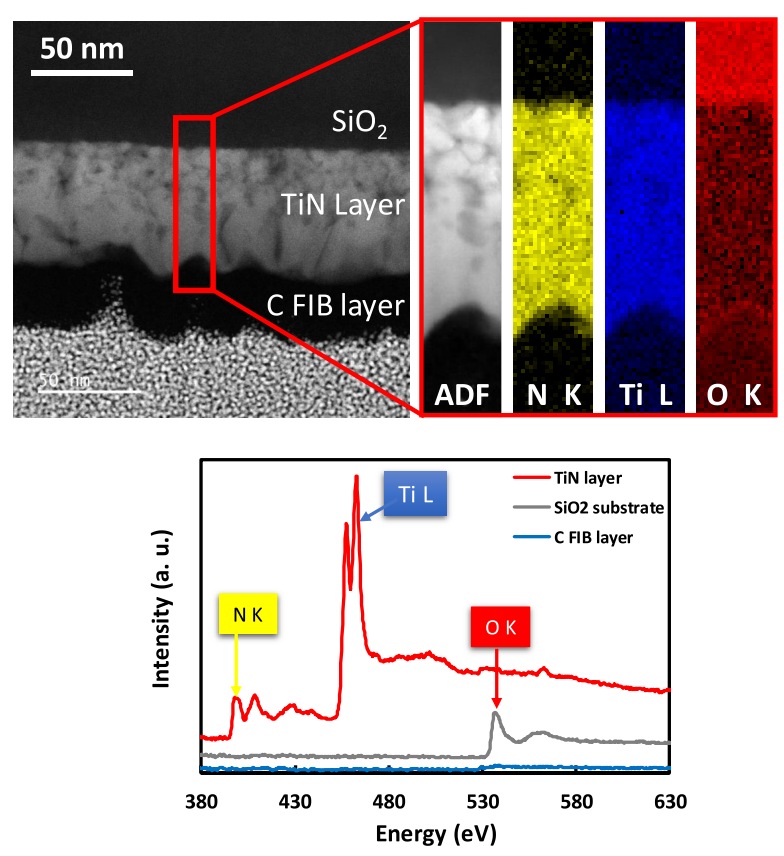

Figure 9. Top: cross-sectional HRTEM of the TiN thin film, annular dark field (ADF), and element mapping images for the $\mathrm{N}, \mathrm{Ti}$, and $\mathrm{O}$ elements in the TiN layer. Bottom: corresponding EELS spectra of $\mathrm{SiO}_{2}, \mathrm{TiN}$, and the protective FIB layer. 
experiments allow us to explain the oxygen EDS signal detected on the nitrided sample. The EELS oxygen mapping based on the oxygen $\mathrm{K}$ edge shows a predictable strong signal in the $\mathrm{SiO}_{2}$ substrate. Nevertheless, an oxygen $\mathrm{K}$ edge was detected everywhere on the FIB lamella, including on the TiN film and on the carbon-protective carbon layer. With respect to the weaker intensity of the $\mathrm{O} \mathrm{K}$ edges on the TiN layer and the protective FIB layers, one can reasonably assume that both the top surface of the TiN layer and the entire surface of the FIB lamella are contaminated by ambient oxygen following the nitridation process and the final FIB lamella step, respectively. The elemental composition of the TiN film was also determined using the EELS Hartree-Slater model. The estimated atomic percentages of each element in the film are $35 \%$ for $\mathrm{Ti}, 64 \%$ for $\mathrm{N}$, and less than $1 \%$ for $\mathrm{O}$. To conclude, EELS data together with EDS characterization provide further evidence that the layer was entirely nitrided in the form of TiN following the nitridation process.

3.3. Microstructuring of Titanium Nitride Films. In the following section, we demonstrate the complete process of direct TiN layer microstructuring from a $\mathrm{TiO}_{2}$ sol-gel-based thin-film layer. We demonstrate that this approach is compatible since the process starts from a direct photo-patternable $\mathrm{TiO}_{2}$ sol-gel. This process has the advantage of being able to rapidly transform $\mathrm{TiO}_{2}$ into $\mathrm{TiN}$ and to avoid annealing in thermal ovens, meaning that the process should be feasible on a wide range of substrates. However, the benefit of this technique goes beyond the diversity of substrates because sol-gel $\mathrm{TiO}_{2}$ can be easily structured by UV exposure, making it possible to obtain TiN (sub)micronic-structured thin films with complex shapes after nitridation. Figure 10A,D shows two patterns in $\mathrm{TiO}_{2}$

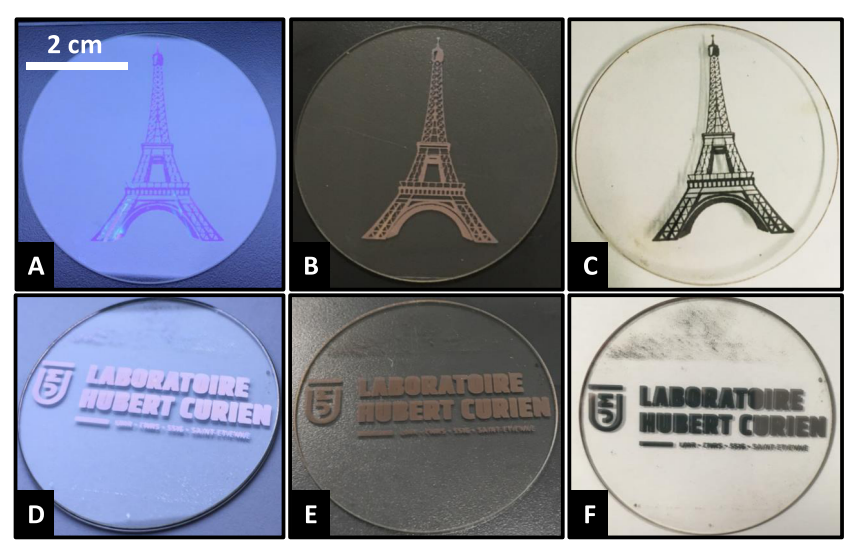

Figure 10. Photographs of structured $\mathrm{TiO}_{2}$ thin films after $\mathrm{UV}$ exposure through photomasks with a slight purple color in reflection $(\mathrm{A}, \mathrm{D})$ and photographs of the same structured films after nitridation with a burnished color in reflection (B, E) or with a grayish color in transmission $(\mathrm{C}, \mathrm{F})$. The thickness of the microstructured $\mathrm{TiO}_{2}$ sol-gel is around $300 \mathrm{~nm}$ and the obtained thickness of the microstructured TiN layer is around $70 \mathrm{~nm}$, which explains the partial transmittance when one looks at the microstructured substrate in transmission.

obtained by UV exposure of a xerogel film through a photomask. The patterns resemble the original photomask. These patterns of $\mathrm{TiO}_{2}$ are then nitrided by the RTA process, described in the previous sections. After treatment, a replica in $\mathrm{TiN}$ of the photomask is obtained (Figure 10B,C,E,F). The whole process takes around $20 \mathrm{~min}$ from the deposition of the $\mathrm{TiO}_{2}$ xerogel to the final nitridation step.
3.4. Nanostructuring of Titanium Nitride Films. To complete the previous discussion, the following section demonstrates the spatial resolution that can be obtained to produce submicron patterns in $\mathrm{TiN}$, which is finally given by $\mathrm{TiO}_{2}$ sol-gel-based lithography. Figure 11A shows the nanostructured $\mathrm{TiO}_{2}$ thin film after $\mathrm{UV}(\lambda=365 \mathrm{~nm})$ illumination and development of the xerogel layer, revealing periodically organized nanopillars that are cylindrical in shape. ${ }^{24,25}$ These nanopillars appear to be fairly regular with dimensions of around $300 \times 500 \mathrm{~nm}$, in agreement with AFM measurements (Figure 11B). The AFM profile also identified a periodicity of about 1 $\mu \mathrm{m}$ induced by the $1 \mu \mathrm{m}$ diameter silica microspheres that are in contact with one another during LB deposition. Higher density of the structure can be envisaged using silica nanospheres with a smaller diameter. After the nitridation step, the AFM measurements (Figure 11C,D) clearly showed the densification effect due to the rapid thermal process. This densification leads to smaller TiN nanopillars with a height of around $80 \mathrm{~nm}$ and a diameter similar to those of the $\mathrm{TiO}_{2}$ nanopillars.

\section{CONCLUSIONS}

In this article, we presented an innovative and direct process to structure TiN thin films involving a directly photo-patternable $\mathrm{TiO}_{2}$ sol-gel layer, which, to our knowledge, has never been published to date. The UV-vis-NIR, Raman, and GIXRD investigations indicated that the structured thin film elaborated from rapid thermal nitridation ( $\mathrm{RTN}$ ) of amorphous $\mathrm{TiO}_{2}$ led to a pure face-centered cubic structure $\mathrm{TiN}$ with weak roughness and a thickness of around $60 \mathrm{~nm}$. The extremely low oxygen content highlighted by the EDS, HRTEM, and EELS results confirmed the formation of a film close to a TiN reference film, and not $\mathrm{TiO}_{x} \mathrm{~N}_{y}$ as obtained in previous studies using a conventional nitridation process. ${ }^{23}$ This has been also demonstrated with ellipsometry measurements, giving almost the same permittivity as that of pure TiN obtained by traditional process deposition. From this study, we have shown that this new nitridation process leads to a TiN layer with interesting properties, even if the optical and metallic characteristics are rather in the lower range of usual TiN films obtained by the physical route. ${ }^{12}$ The residual porosity, inherent to the sol-gel route, coupled with the low thickness of the TiN layer, could explain these lower values. Further studies on the nitriding conditions could be carried out to improve the material properties. The main advantage of this method over traditional ammonolysis is how easy it is to produce the TiN component from a sol-gel approach in a much shorter time (a few minutes for RTN compared to several hours for the conventional nitridation process), implying that the process also requires less energy and gas. To conclude, this work demonstrated an affordable, effective, and practicable way to convert complex $\mathrm{TiO}_{2}$ shapes into a pure TiN-structured material. Indeed, the processing time and the equipment required are fully compatible with most manufacturing processes, whereas the traditional ammonolysis process requires a lot of time, large quantities of consumables, and heavy equipment. The low film thickness of the TiN film obtained by this process may be presently a limitation for using such films as diffusion barriers in microelectronic devices. Thus, future developments may be focused in particular on obtaining thicker TiN films with similar characteristics. In spite of this limitation, this technology promises to achieve very high-quality $\mathrm{TiN}$ micro-nanostructured thin films, including on nonconventional substrates 

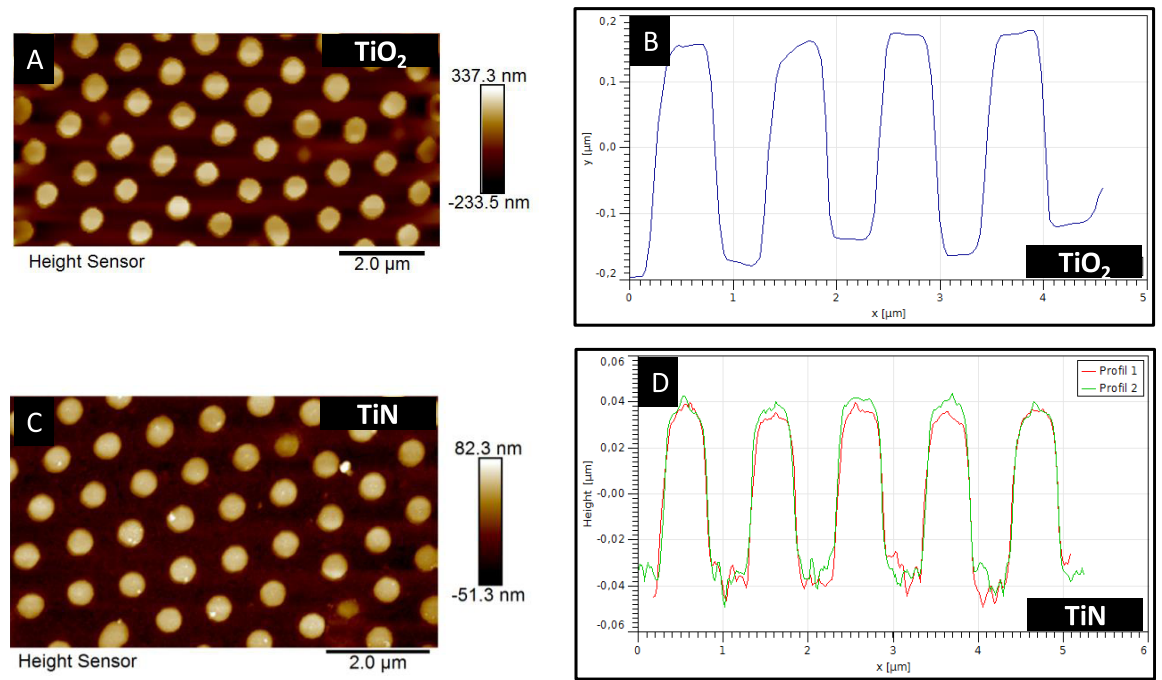

Figure 11. (A, B) AFM image and profile of nanostructured $\mathrm{TiO}_{2}$ and (C, D) AFM image and profile of nanostructured TiN.

such as glass or plastic, even if the factor of temperature can be a strong limitation for thermo-sensitive materials.

\section{ASSOCIATED CONTENT}

\section{SI Supporting Information}

The Supporting Information is available free of charge at https://pubs.acs.org/doi/10.1021/acs.jpcc.0c07157.

Additional information on the AFM measurements of $\mathrm{TiO}_{2}$ and $\mathrm{TiN}$ thin films deposited on a $\mathrm{SiO}_{2}$ substrate and description of the ellipsometry experimental setup (PDF)

\section{AUTHOR INFORMATION}

\section{Corresponding Authors}

Nicolas Crespo-Monteiro - Universite de Lyon, Laboratoire Hubert Curien, UMR CNRS 5516, 42000 Saint-Etienne, France; Email: nicolas.crespo.monteiro@univ-st-etienne.fr

Yves Jourlin - Université de Lyon, Laboratoire Hubert Curien, UMR CNRS 5516, 42000 Saint-Etienne, France;

Email: yves.jourlin@univ-st-etienne.fr

\section{Authors}

Arnaud Valour - Universite de Lyon, Laboratoire Hubert Curien, UMR CNRS 5516, 42000 Saint-Etienne, France; 이이.org/ 0000-0003-1152-1277

Maria A. Usuga Higuita - Universite de Lyon, Laboratoire Hubert Curien, UMR CNRS 5516, 42000 Saint-Etienne, France; (1) orcid.org/0000-0002-9423-5673

Stéphanie Reynaud - Université de Lyon, Laboratoire Hubert Curien, UMR CNRS 5516, 42000 Saint-Etienne, France

Marion Hochedel - Universite de Lyon, Laboratoire Hubert Curien, UMR CNRS 5516, 42000 Saint-Etienne, France

Damien Jamon - Université de Lyon, Laboratoire Hubert Curien, UMR CNRS 5516, 42000 Saint-Etienne, France

Christophe Donnet - Université de Lyon, Laboratoire Hubert Curien, UMR CNRS 5516, 42000 Saint-Etienne, France

Complete contact information is available at: https://pubs.acs.org/10.1021/acs.jpcc.0c07157

\section{Author Contributions}

This manuscript was written through contributions of all authors. All authors have given approval to the final version of the manuscript.

\section{Notes}

The authors declare no competing financial interest.

\section{ACKNOWLEDGMENTS}

This work was financially supported by the project MICROSOLEN in the "Pack Ambition Recherche" framework from the Region Rhône Alpes Auvergne, as well as the NOTAIR project financed by the CNRS PEPS program. This work was partly supported by the French RENATECH+ network led by the CNRS, on the Nano Saint Etienne platform.

\section{REFERENCES}

(1) Choudhury, S. M.; Wang, D.; Chaudhuri, K.; DeVault, C.; Kildishev, A. V.; Boltasseva, A.; Shalaev, V. M. Material Platforms for Optical Metasurfaces. Nanophotonics 2018, 7, 959-987.

(2) Kildishev, A. V.; Boltasseva, A.; Shalaev, V. M. Planar Photonics with Metasurfaces. Science 2013, 339, No. 1232009.

(3) Walia, S.; Shah, C. M.; Gutruf, P.; Nili, H.; Chowdhury, D. R.; Withayachumnankul, W.; Bhaskaran, M.; Sriram, S. Flexible Metasurfaces and Metamaterials: A Review of Materials and Fabrication Processes at Micro- and Nano-Scales. Appl. Phys. Rev. 2015, 2, No. 011303.

(4) Chen, X.; Huang, L.; Mühlenbernd, H.; Li, G.; Bai, B.; Tan, Q.; Jin, G.; Qiu, C.-W.; Zhang, S.; Zentgraf, T. Dual-Polarity Plasmonic Metalens for Visible Light. Nat. Commun. 2012, 3, No. 1198.

(5) Naik, G. V.; Schroeder, J. L.; Ni, X.; Kildishev, A. V.; Sands, T. D.; Boltasseva, A. Titanium Nitride as a Plasmonic Material for Visible and Near-Infrared Wavelengths. Opt. Mater. Express 2012, 2, 478-489.

(6) Li, W.; Guler, U.; Kinsey, N.; Naik, G. V.; Boltasseva, A.; Guan, J.; Shalaev, V. M.; Kildishev, A. V. Refractory Plasmonics with Titanium Nitride: Broadband Metamaterial Absorber. Adv. Mater. 2014, 26, 7959-7965.

(7) Kim, T.-S.; Park, S.-S.; Lee, B.-T. Characterization of NanoStructured TiN Thin Films Prepared by R.F. Magnetron Sputtering. Mater. Lett. 2005, 59, 3929-3932.

(8) Jafari, A.; Ghoranneviss, Z.; Elahi, A. S.; Ghoranneviss, M.; Yazdi, N. F.; Rezaei, A. Effects of Annealing on TiN Thin Film Growth by DC Magnetron Sputtering. Adv. Mech. Eng. 2014, 6, No. 373847.

(9) Naik, G. V.; Saha, B.; Liu, J.; Saber, S. M.; Stach, E. A.; Irudayaraj, J. M. K.; Sands, T. D.; Shalaev, V. M.; Boltasseva, A. Epitaxial Superlattices with Titanium Nitride as a Plasmonic Component for 
Optical Hyperbolic Metamaterials. Proc. Natl. Acad. Sci. U.S.A. 2014, 111, 7546-7551.

(10) Prayakarao, S.; Robbins, S.; Kinsey, N.; Boltasseva, A.; Shalaev, V. M.; Wiesner, U. B.; Bonner, C. E.; Hussain, R.; Noginova, N.; Noginov, M. A. Gyroidal Titanium Nitride as Nonmetallic Metamaterial. Opt. Mater. Express 2015, 5, 1316-1322.

(11) Krockenberger, Y.; Karimoto, S.; Yamamoto, H.; Semba, K. Coherent Growth of Superconducting TiN Thin Films by Plasma Enhanced Molecular Beam Epitaxy. J. Appl. Phys. 2012, 112, No. 083920.

(12) Guo, W.-P.; Mishra, R.; Cheng, C.-W.; Wu, B.-H.; Chen, L.-J.; Lin, M.-T.; Gwo, S. Titanium Nitride Epitaxial Films as a Plasmonic Material Platform: Alternative to Gold. ACS Photonics 2019, 6, 18481854.

(13) Rebenne, H. E.; Bhat, D. G. Review of CVD TiN Coatings for Wear-Resistant Applications: Deposition Processes, Properties and Performance. Surf. Coat. Technol. 1994, 63, 1-13.

(14) Fix, R.; Gordon, R. G.; Hoffman, D. M. Chemical Vapor Deposition of Titanium, Zirconium, and Hafnium Nitride Thin Films. Chem. Mater. 1991, 3, 1138-1148.

(15) Su, J.; Boichot, R.; Blanquet, E.; Mercier, F.; Pons, M. Chemical Vapor Deposition of Titanium Nitride Thin Films: Kinetics and Experiments. CrystEngComm 2019, 21, 3974-3981.

(16) Langereis, E.; Heil, S. B. S.; van de Sanden, M. C. M.; Kessels, W. M. M. In Situ Spectroscopic Ellipsometry Study on the Growth of Ultrathin TiN Films by Plasma-Assisted Atomic Layer Deposition. J. Appl. Phys. 2006, 100, No. 023534.

(17) Briggs, J. A.; Naik, G. V.; Petach, T. A.; Baum, B. K.; GoldhaberGordon, D.; Dionne, J. A. Fully CMOS-Compatible Titanium Nitride Nanoantennas. Appl. Phys. Lett. 2016, 108, No. 051110.

(18) Shkondin, E.; Repän, T.; Takayama, O.; Lavrinenko, A. V. High Aspect Ratio Titanium Nitride Trench Structures as Plasmonic Biosensor. Opt. Mater. Express 2017, 7, 4171-4182.

(19) Yu, I.-S.; Cheng, H.-E.; Chang, C.-C.; Lin, Y.-W.; Chen, H.-T.; Wang, Y.-C.; Yang, Z.-P. Substrate-Insensitive Atomic Layer Deposition of Plasmonic Titanium Nitride Films. Opt. Mater. Express 2017, 7, $777-784$.

(20) Murai, S.; Fujita, K.; Daido, Y.; Yasuhara, R.; Kamakura, R.; Tanaka, K. Plasmonic Arrays of Titanium Nitride Nanoparticles Fabricated from Epitaxial Thin Films. Opt. Express 2016, 24, 11431153.

(21) Sugavaneshwar, R. P.; Ishii, S.; Dao, T. D.; Ohi, A.; Nabatame, T.; Nagao, T. Fabrication of Highly Metallic TiN Films by Pulsed Laser Deposition Method for Plasmonic Applications. ACS Photonics 2018, 5, 814-819.

(22) Torgovkin, A.; Chaudhuri, S.; Ruhtinas, A.; Lahtinen, M.; Sajavaara, T.; Maasilta, I. J. High Quality Superconducting Titanium Nitride Thin Film Growth Using Infrared Pulsed Laser Deposition. Supercond. Sci. Technol. 2018, 31, No. 055017.

(23) Berthod, L.; Gâté, V.; Bichotte, M.; Langlet, M.; Vocanson, F.; Jimenez, C.; Jamon, D.; Verrier, I.; Veillas, C.; Parriaux, O.; Jourlin, Y. Direct Fabrication of a Metal-like TiN-Based Plasmonic Grating Using Nitridation of a Photo-Patternable $\mathrm{TiO}_{2}$ Sol-Gel Film. Opt. Mater. Express 2016, 6, 2508-2520.

(24) Shavdina, O.; Berthod, L.; Kämpfe, T.; Reynaud, S.; Veillas, C.; Verrier, I.; Langlet, M.; Vocanson, F.; Fugier, P.; Jourlin, Y.; Dellea, O. Large Area Fabrication of Periodic $\mathrm{TiO}_{2}$ Nanopillars Using Microsphere Photolithography on a Photopatternable Sol-Gel Film. Langmuir 2015, 31, 7877-7884.

(25) Berthod, L.; Shavdina, O.; Vocanson, F.; Langlet, M.; Dellea, O.; Veillas, C.; Reynaud, S.; Verrier, I.; Jourlin, Y. Colloidal Photolithography Applied to Functional Microstructure on Cylinder Based on Photopatternable $\mathrm{TiO}_{2}$ Sol-Gel. Microelectron. Eng. 2017, 177, 4651.

(26) Berthod, L.; Bichotte, M.; Verrier, I.; Veillas, C.; Kämpfe, T.; Vocanson, F.; Langlet, M.; Laukkanen, J.; Parriaux, O.; Jourlin, Y. Efficient Reversible Phase Mask for $\mathrm{TiO}_{2}$ Submicron Gratings Directly Printed on Cylindrical Surfaces. Opt. Express 2017, 25, 9003-9009.
(27) Kamiya, K.; Nishijima, T.; Tanaka, K. Nitridation of the SolGel-Derived Titanium Oxide Films by Heating in Ammonia Gas. J. Am. Ceram. Soc. 1990, 73, 2750-2752.

(28) Kohno, K. Nitridation of the Sol-Gel Derived $\mathrm{TiO}_{2}$ Coating Films and the Infrared Ray Reflection. J. Mater. Sci. 1992, 27, 658-660.

(29) Jiménez, C.; Langlet, M. Formation of TiN by Nitridation of $\mathrm{TiO}_{2}$ Films Deposited by Ultrasonically Assisted Sol-Gel Technique. Surf. Coat. Technol. 1994, 68-69, 249-252.

(30) Briche, S.; Tebby, Z.; Riassetto, D.; Messaoud, M.; Gamet, E.; Pernot, E.; Roussel, H.; Dellea, O.; Jourlin, Y.; Langlet, M. New Insights in Photo-Patterned Sol-Gel-Derived $\mathrm{TiO}_{2}$ Films. J. Mater. Sci. 2011, $46,1474-1486$

(31) Gâté, V.; Jourlin, Y.; Vocanson, F.; Dellea, O.; Vercasson, G.; Reynaud, S.; Riassetto, D.; Langlet, M. Sub-Micrometric Patterns Written Using a DIL Method Coupled to a $\mathrm{TiO}_{2}$ Photo-Resist. Opt. Mater. 2013, 35, 1706-1713.

(32) Kamiya, K.; Yoko, T.; Bessho, M. Nitridation of $\mathrm{TiO}_{2}$ Fibres Prepared by the Sol-Gel Method. J. Mater. Sci. 1987, 22, 937-941.

(33) Swanepoel, R. Determination of the Thickness and Optical Constants of Amorphous Silicon. J. Phys. E: Sci. Instrum. 1983, 16, 1214-1222.

(34) Oda, S.; Uchiyama, H.; Kozuka, H. Thermoplasticity of Sol-GelDerived Titanoxanes Chemically Modified with Benzoylacetone. J. SolGel Sci. Technol. 2014, 70, 441-450.

(35) Bertoni, G.; Beyers, E.; Verbeeck, J.; Mertens, M.; Cool, P.; Vansant, E. F.; Van Tendeloo, G. Quantification of Crystalline and Amorphous Content in Porous $\mathrm{TiO}_{2}$ Samples from Electron Energy Loss Spectroscopy. Ultramicroscopy 2006, 106, 630-635.

(36) Pflüger, J.; Fink, J.; Weber, W.; Bohnen, K. P.; Crecelius, G. Dielectric Properties of $\mathrm{TiC}_{x}, \mathrm{TiN}_{x}, \mathrm{VC}_{x}$, and $\mathrm{VN}_{\mathrm{x}}$ from 1.5 to $40 \mathrm{eV}$ Determined by Electron-Energy-Loss Spectroscopy. Phys. Rev. B 1984, 30, No. 1155.

(37) Chang, C.-C.; Nogan, J.; Yang, Z.-P.; Kort-Kamp, W. J. M.; Ross, W.; Luk, T. S.; Dalvit, D. A. R.; Azad, A. K.; Chen, H.-T. Highly Plasmonic Titanium Nitride by Room-Temperature Sputtering. Sci. Rep. 2019, 9, No. 15287.

(38) Zgrabik, C. M.; Hu, E. L. Optimization of Sputtered Titanium Nitride as a Tunable Metal for Plasmonic Applications. Opt. Mater. Express 2015, 5, 2786-2797.

(39) Spengler, W.; Kaiser, R.; Christensen, A. N.; Müller-Vogt, G. Raman Scattering, Superconductivity, and Phonon Density of States of Stoichiometric and Nonstoichiometric TiN. Phys. Rev. B 1978, 17, No. 1095.

(40) Chen, C. C.; Liang, N. T.; Tse, W. S.; Chen, I. Y.; Duh, J. G. Raman Spectra of Titanium Nitride Thin Films. Chin. J. Phys. 1994, 32, 205-210.

(41) Constable, C. P.; Yarwood, J.; Münz, W.-D. Raman Microscopic Studies of PVD Hard Coatings. Surf. Coat. Technol. 1999, 116-119, 155-159.

(42) International Centre for Diffraction Data. Database PDF-4, Newtown Square, PA, USA, http://www.icdd.com/.

(43) Wyckoff, R. W. G. Crystal Structures, 2nd ed.; Interscience Publishers: New York, New York, 1963; Vol. 1, pp 85-237. 